\title{
AUTUMN QUARTERLY MEETING 1978
}

The Autumn Quarterly Meeting was held in London, at the London Hospital Medical College and the Royal Society of Medicine, on 16 and 17 November 1978, under the Presidency of Professor Desmond Pond.

\section{Scientific Meetings}

On Thursday, 16 November, meetings were held at the London Hospital Medical College, and the following papers were presented:

\section{Biological Aspects of Depression:}

The role of neuro-transmitters in controlling hormonal release in depression, Dr S. Checkley; The changes in pituitary function associated with depression: cause or effect? Professor B. T. Donovan; Utilization and distrubution of tryptophan in patients with unipolar affective disorders, Dr D. M. Shaw; The use of psychotropic drugs in the management of depression in general practice, Dr Paul Williams.

Psychiatric Aspects of Adolescence:

The presentation of adolescent, psychiatric problems in general practice, $\mathrm{Dr}$ Wendy Greengross; The adolescent who responds to lithium, $\mathrm{Dr} B$. Lena; The adolescent-a paper tiger? Dr J. Coleman; A social and attitudinal survey of young adolescent pregnant girls, Dr Dorothy Black.

\section{Marital and Sexual Problems:}

Assessment and diagnosis of sexual and marital dysfunction before treatment, $\mathrm{Dr} \mathrm{M}$. T. Haslam; Behavioural approaches to marital problems, Dr M.J. Crowe; Teaching of the management of sexual dysfunction, $\mathrm{Dr} T$. Betts; What are the criteria for terminating the treatment of sexual dysfunction? $\mathrm{Dr}$ Paul Brown.

Violence:

The aetiology of wife battering, Dr J. Gayford; Rape, Professor T. C. N. Gibbens; A study of patients behaving violently in psychiatric hospitals, $\mathrm{Dr} \mathrm{E}$. Fottrell; Aftermath neurosis-sequelae of bombing, Dr A. C. P. Sims.

At the meeting of the Psychotherapy Section, Dr Irving S. Kreeger presented the Chairman's Address: 'The Degree of Skill in Psychotherapy necessary for every Psychiatrist'.

The following papers were presented at the meeting of the Dependence/Addiction Group: What do we mean by treatment for Alcoholism? Dr J. Orford;
Alcoholism in the West of Scotland, Drs P. Kershaw and W. Saunders; Drug Problems at Casualty Units, Dr H. Ghodse.

On Friday, 17 November in the morning the following papers were read at the Royal Society of Medicine: Psychological Aspects of Gambling, Mr Derek Cornish. Pathological Gambling and Society, Dr E. Moran.

Following lunch, at which the President and Officers entertained the Maudsley Lecturer, Professor SEYmour KETY delivered the Maudsley Lecture entitled 'The Syndrome of Schizophrenia: Unresolved Questions and Opportunities for Research'. The vote of thanks was proposed by $\operatorname{Dr}$ A. J. Coppen.

\section{Business Meeting}

The Business Meeting was held on 17 November.

\section{Obituary}

The Registrar announced with regret the death of the following members:

James Amor Ardis, Consultant Psychiatrist, Hull Clinical Area \& De La Pole Hospital.

Stanley William George Caseley, M. M., Medical Superintendent, Komani Hospital, Queens Town, Cape, South Africa.

Theodore Egan Hurley, Consultant Psychiatrist, Hospital of St John of God, Silverdale, Carnforth, Lancs.

Sean McDermott Murphy, Consultant Psychiatrist, St Finan's Hospital, Killarney, Co Kerry, Eire.

LORd Platt (ROBERT), Formerly Professor of Medicine, University of Manchester; Honorary Fellow.

David Price-Williams, Medical Adviser, John Wyeth \& Brother Ltd., Amersham, Bucks.

LEON RADClyfFe, Formerly Medical Officer, Napsbury Hospital, Herts.

Gerald JOSEPH Rockley, Consultant Psychiatrist, Prestwich Hospital, Manchester.

Kenneth Stewart, Consultant in Child Psychiatry, Northampton \& Kettering Hospital Groups.

Salo Tischler, Consultant Psychiatrist, The Child Guidance Centre, London, \& High Wick Hospital, St Albans.

Angus Ewan Tulloch, S.H.O., Hellesdon Hospital, Norwich.

Alexander Thomson Macbeth Wilson, Professor, London Graduate School of Business Studies, London, NW1. 


\section{Minutes}

The Minutes of the previous meeting, held in Dublin on 25 and 26 April 1978, and published in the Bulletin November 1978 were approved and signed by the President.

\section{REGISTRAR'S REPORT}

Dr TIMBURy read the following Report:

'It gives me pleasure to present my first report since assuming office as Registrar last July. My first task is to acknowledge the devoted service to the College of my predecessor, Dr Morris Markowe, and his help to me during the transition period.

Council met on 20 October, and the Executive and Finance Committee has met on four occasions since Dr. Markowe gave his last report.

The regular work of the College, which was reviewed in detail in the Sixth Annual Report published in July 1978, has continued, and a number of new matters have been considered.

Because of the importance of manpower questions, Council has agreed that the Manpower Committee should become a Special Committee of Council, and the first meeting of the new Committee, chaired by Dr Ashley Robin, was held on 7 November.

Dr Peter Sainsbury has held several meetings of the Special Committee of which he is Chairman, which is studying the problems of dissenters and the alleged abuse of psychiatry for political purposes.

Council has also agreed to revive our joint working party with the Royal College of General Practitioners because of the increasing amount of work of mutual interest, particularly related to the vocational training of general practitioners.

Dr E. Moran's Special Committee which gave the College's evidence to the Royal Commission on Gambling is now studying the Commission's Report.

The College has sent further comments on the Butler Report to the DHSS.

You will have read in the Bulletin that the President has called for a special two day meeting of members of Council to be held in February. Divisions and Sections have been asked to brief their representatives with their views on the various topics to be discussed. These will include College organization, manpower, public relations, continuing education and medical audit, the implications of current research findings, and future trends in the provision of psychiatric services.

The Court of Electors has begun to review our procedures for appointing College Assessors to Advisory Appointments Committees. Revised guidelines for these assessors are also in preparation. The duties of College Regional Advisers are also being studied, and a meeting of Advisers will be held early next year.
A Special Committee under the chairmanship of $\mathrm{Dr}$ Robert Bluglass is giving urgent and detailed consideration to the College's response to the recent White Paper on the Review of the Mental Health Act, and we plan to make a public statement about this as soon as possible and also on the Report on Mental Health Review Tribunals.

The College's Report on Alcohol and Alcoholism which was prepared by the Special Committee under the chairmanship of $\mathrm{Dr}$ Griffith Edwards will be published in January.

Work has resumed on the College's mini-computer, and I hope that after much disappointing delay it will be in operation early in 1979. I would ask members to bear with me if I am forced to ask them to update the information on their addresses and qualifications which they so readily provided when the computer was first proposed 18 months ago.

The House Committee has been looking at ways and means of continuing to refurbish our accommodation at 17 Belgrave Square. I hope that further improvements can be undertaken soon to provide better facilities for members and staff.

I have recently received letters from a number of members who have asked me to suggest that sections of general psychiatric textbooks which deal with mental handicap should be looked at by specialists in the field before such books are widely recommended.

The Joint Committee on Higher Psychiatric Training is continuing its programme of inspection of senior registrar and honorary senior registrar posts throughout the country. The new Chairman of that Committee is Professor Kenneth Rawnsley, and the Secretary is Professor Sydney Brandon.

There have been a number of new appointments to the staff at Belgrave Square and we are almost at full strength for the first time for many months. We welcome these new members and acknowledge with gratitude the additional work which has been undertaken by our loyal staff during the period of shortage and difficulty. It would be wrong to mention particular names but College members are grateful to them all for their hard work on our behalf.'

\section{RESOLUTION}

The following Resolution proposed by Dr Harold Bourne and seconded by Dr David Shaw was carried nem con:

'The Royal College of Psychiatrists reiterates its concern over the abuse of psychiatry for the suppression of dissent in the Soviet Union and applauds the courage of those Soviet citizens who have taken an open stand against such abuse. In particular it expresses its admiration and support for the following individuals: 
1. Semyon Gluzman, Psychiatrist, whose continued imprisonment in defiance of international protest it again deplores;

2. Alexander Podrabinex, Medical Assistant, whose research into the abuse of psychiatry and whose book Punitive Medicine has led to judicial persecution and now to a sentence of exile;

3. Alexander Voloshanovich, Psychiatrist, whose clinical reports have been invaluable for the brave work in Moscow of the Working Commission to Investigate the Use of Psychiatry for Political Purposes:

4. Vladimir Moskalkov, Psychiatrist, whose testimony in support of Alexander Podrabinek at his trial supplied a most worthy example of ethical medical behaviour.'

\section{ASSESSORS' REPORTS ON ADVISORY APPOINTMENTS COMMITTEES}

Since 1970, College assessors on consultant appointments committees have been asked to supply information on a confidential basis about applicants and those interviewed. The information includes the number of applicants, assessors' opinions on their training and experience, numbers interviewed, their quality, and the main deficiencies of all those seen; finally, the number of overseas graduates applying or short-listed. In addition, the assessors are asked to make any general comments about the interview, and these have sometimes taken the form of a letter or memorandum, paricularly when the assessor has felt unhappy about the candidate appointed.

An analysis has been made of 395 returns (from 56 per cent response rate) from England and Wales for the years $1974-7$ covering all specialties.

\section{Results}

These are presented in summary form in Tables 1, 2 and 3. The proportion of posts where no one was appointed was wide-ranging, from 8 per cent for psychotherapy to 42 per cent for subnormality. What is of interest is that six jobs in psychogeriatrics were unfilled because of deficiencies in the post rather than in the candidates. Deficiencies in the posts were also mentioned twice for subnormality and once for general psychiatry.

The most frequently mentioned deficiencies in the candidates were in experience and training, including experience in general psychiatry in those applying for specialist posts; less frequently personality and language problems were mentioned. In detail, inadequate experience was mentioned $77,36,39,13$, 10,5 and 8 times in general, child, subnormality, psychogeriatrics, forensic and the dependencies respectively. The corresponding figures for personality problems showed a much wider range, being $34,4,10$, $3,3,3$ and 0 . Deficiencies in comprehension and the use of English were commented on in the returns of 9 general psychiatry, 8 subnormality and 3 child psychiatry interviews.

No detailed analysis was made of which areas and what types of post were least and most successful in attracting good candidates, but the impression, which will come as no surprise, is that teaching hospitals on the whole fared better than non-teaching ones and that posts in the South and South-West even for nonteaching hospitals attracted a larger share of wellqualified candidates than posts in the Midlands and the North.

What changes have there been over time? Because of the small numbers a detailed analysis was made for general psychiatry only. There has perhaps been a slight rise in the number of very good and good interviewees, with a correspondingly slight fall in the indifferent and poor ones, but the results as shown in Table 2 are not entirely consistent. The mean number of applicants per post for general psychiatry has shown a consistent fall over the four years analysed.

Impressionistically, there has been a definite improvement in the calibre of those applying in the specialties of forensic psychiatry, psychotherapy and the addictions, while the proportion of unfilled posts in psychogeriatrics has dropped over the years. For example, in 1974 four posts only were filled out of seven.

\section{Conclusions}

The returns make far from happy reading. Too many of the senior registrars applying have had quite inadequate experience, at least in the view of the College assessor, and there are frequent comments on 